could not maintain the eyes open, nor hold up her head. Placed upright, unless supported, she would have sunk down. She insisted that she was quite able to walk, but on making the attempt, it proved otherwise. She now appeared to be, for the first time, conscious that something unusual had happened to her-" she felt very strange;" and that her head was confused. She was removed to her own apartment, was restless, and suffered from headach during the night; scarcely slept, and awoke in the morning as if from a dream, the particulars of which she could not recollect. On being informed of the proceedings of the previous evening, she was amazed; and her vexation would probably have exceeded her amazement, but for the assurance of her friends who had been present, that she herself needed not to regret one of the many thoughts she had so strangely disclosed.

Was the apparent absence of correct appreciation of surrounding circumstances in this case genuine, or was it assumed, in order to gratify some mental craving for effect, so common a characteristic of hysterical girls? I am unable to furnish to the reader any proof which ought to satisfy him, but I am myself perfectly satisfied that nothing was feigned. The patient is neither nervous, hysterical, nor in delicate health; she is tall and stout, and strong both in body and mind. Her manner of expressing her opinion during her ether-dreaming, though free from the slightest immodesty, was far removed from the reserve which a knowledge of the presence of those around would have occasioned. Communications were unhesitatingly made, which, though proper enough under the circumstances assumed by the lady at the moment, would certainly have been withheld had she really known of the truth. But, whether feigned or real, an hysterical vagary or an ether-trance, the state induced was singular, and deserving of investigation. There was great impairment of volitional power; the dropped eyelids were evidently not spasmodically closed, but merely unraised by the relaxation of the voluntary elevator muscle leaving the sphincter palpebrarum without an antagonist. The head fell passively when raised, and the limbs were lax, and gave way. There was no deficiency of spinal nervous power, since a female friend, by tickling the patient under the arms, caused her to start and move the arms with an expression of displeasure. Nor was the power of the will over mental action diminished; opinions were stated with unusual decision. The expression of the countenance altered in exact accordance with the change of thought; language was more fluent and emphatic than usual; apprehension quick, and reasoning very clear and correct. Still there was nothing greater in all this than can be ascribed to perfect freedom from consciousness of the circumstances; and nothing more, probably, than the same individual could at any time display, if she thought proper, and could - which is doubtful-feel equally unshackled in sentiment in the presence of others. Assuming that consciousness was not complete, still it was quite perfect as far as it did exist. There was perfect consciousness of the tenour of the remarks addressed. The chief peculiarity seemed to be that all the ideas were induced by suggestion in the first instance; a fresh train never originated spontaneously, though the tenour of thought could be changed instantly by a fresh suggestion, or by mechanically altering the posture-i.e., suggesting by means of external sensation. Traction was not tried; prediction was asked for, and ridiculed by the patient. It was impossible to make the lady talk nonsense. In these respects, the case differs from many examples of Mesmeric trance. Nor does it approach in wonderfulness the superhuman manifestations of increased intellectuality, described by the Rev. Mr. Sandby and others. The only demand which it makes on our belief is, that by means of ether we may occasionally excite a condition of brain in which consciousness is not sufficient to control the mind; and in which the mind is rendered as acute as the nature of the person will admit of. Is this a state of mere intoxication? If we choose so to designate it, we must bear in mind, that in drunkenness, to the extent of suspending consciousness, the thoughts are not remarkable for their acuteness, the speech for its distinctness and fluency, nor the countenance for its intellectual expression. If intoxication at all, then, this is of a much more spiritual character than the common kind. Indeed, a moment's consideration will show, that to say of this and of similar instances they are "mere hysteria," "fits of intoxication," "boarding-school pranks," and so on, neither explains their nature, nor lessens their singularity. If we can almost at any time produce the given condition of mind in an individual who never at any other time thinks fit to manifest a similar state, the fact is worth noting by the profession, and by society at large.
After examining at considerable length the statements of the mesmerists, I was formerly led to conclude that all the ascertained and probable cffects of mesmeric procedure depended on a peculiar state of the nervous system, which might be induced in a variety of ways, and not upon any imagined thuid given by the operator to his patient. That insensibility to pain, as the result of so infiuencing the nervous system, was "possible, but not very probable."* That the so-called higher phenomena of mesmerisin were impossible and quite incredible. The discovery of the effects of ether has furnished additional data. We are now warrunted in acknowledging that sensibility may be entirely suspended for a time by artificial means. We have a new field opened for the investigation of the action of the mind, but, so far, not a single fact to lessen our incredulity as to the sublime absurdities of clairvoyance and prevision.

Cheshire, March, 1847.

\section{ON THE ADMINISTRATION OF MERCURY IN SYPHILIS.}

\section{BY HOLMES COOTE, EsQ., F.R.C.S.E.}

The treatment of syphilis by mercury, in the form of external applications, seems, from the writings of the physicians of the fifteenth century, to have been in vogue very shortly after the disease was recognised and described as the morbus Gallicus, between the years 1494-96. The fears, which had existed from very early times, as to the injurious effects which this mineral might produce upon the human frame, combined with the disastrous consequences following its reckless administration by uneducated itinerant quacks, deterred the profession from employing it internally, till about the middle of the sixteenth century, when it had been ascertained that guiacum, sarsaparilla, and other much vaunted remedies, were inefficient in controlling the progress of this dreaded malady. Since that time, so numerous are the authors who have recorded the results of their experience upon the subject, and so different are their conclusions, that a host of learned names can with readiness be brought forward to support almost every shade of opinion which exists at the present day. The favourable view taken by Astrue of the superior efficacy of mercury over all other known medicines in the treatment of syphilis, received support from John Hunter, who unfortunately went one step too far in maintaining the absolute necessity of its employment to arrest the morbid action of the venereal poison. Although it has been clearly proved, chiefly by the investigations of the army surgeons, that all syphilitic sores may be successfully treated by simple measures, and that the greater number will, if left to pursue their own course, heal in a short space of time, so implicitly has the doctrine of John Hunter been received by the profession, and so eagerly espoused by the public at large, that it will take some generations before this popular impression will pass away. The very great importance of clearly establishing the accuracy or the inaccuracy of the opinion which ascribes to mercury the wonderful property of eradicating and destroying a poison, by which the whole frame has become infected, cannot be better shown than by drawing attention to the consequences which naturally result, if this statement is founded in error. Let us suppose that a patient who has contracted syphilis, places himself, soon after the first manifestation of the disease, under the care of a surgeon, by whose direction he commences a course of mercury, under which the primary sore heals; the administration of the mercury is continued some weeks longer, and the patient is then pronounced free from all risk of secondary symptoms. Trusting to this opinion, he may unintentionally infect an innocent person, and even his own offspring. Whether the patient himself suffer from secondary disease, or whether he communicate it to others, it is the surgeon who receives the blame; and it is a singular fact, one which well illustrates the unsettled state of opinion upon this subject, that precisely the same set of symptoms will by one set of practitioners be ascribed to the fact of the mercurial course not having been pushed far enough, and by another, to the unfavourable influence of mercury upon the constitution.

For the elucidation of these important points, neither argument nor reference to authorities can be of material use. We must rely almost entirely upon the impartial observation and record of cases, which, watched for a considerable number of years, will afford us a ready solution of those difficulties by which we are now surrounded. Commencing in the year 1843 , I took, with the permission of Mr. Skey, the particulars of fifty consecutive cases of patients suffering from severe 
secondary or tertiary symptoms. Inquiring minutely into their histories, and often cross-questioning different members of the same finmily, I adopted every possible precantion against errors From the list thus formed, I select the following, of which the remainder are but repetitions. In each case the number of attacks, both primary and secondary, from which the patients have erer suffered, is carefully mentioned.

CASE 1.-Samuel $\mathrm{H}-$ - ; states, that four months ago he noticed, a tew days after cxposure to venereal infection, a series of small sores round the corona glandis. For t wo months he took a pill, containing mercury, twice a day; and he states, that during the whole period, the gums were more or less swelled and tender. The sores healed speedily, but the salivation was continued some weeks after their cicatrization, that he might be protected against the occurrence of secondary symptoms.

Oct. 25th, 1843.- - He became out-patient, with syphilitic enlargement of the testicles, and an eruption of rupial spots over the whole body.

CASE 2.- Henry B- states that he contracted syphilis thirteen years ago, when he suffered severely from a large primary sore, which healed after a three months' salivation. A large cicatrix occupies the extremity of the glans penis and the orifice of the urethra.

Oct. 25 th, 1843.--He became out-patient, with a large periosteal swelling of the left tibia, attended with severe nocturnal pains and two foul ulcers of the leg, formed by mortification of a portion of integument over two patches of sloughed cellular tissue.

CASE 3.-Henry ML - was salivated over a period of four months, three years ago, for some slight primary affection, which has left no trace behind.

November, 1843. - He became out-patient, with an eruption, partly papular, partly tubercular, over the whole body, with sponginess of the gums, looseness of the teeth, foetid breath, and constant flow of saliva.

CASE 4.--William M- states, that four montlis ago he suffered from a syphilitic sore, which healed undor the influence of mercury. He took three pills a day for about tour months. The gums were tender during the whole time.

Nov. 1843. - He became out-patient, with a periosteal swelling of the left tibia.

CASE 5.-Charles G- states, that twelve months ago he suffered from a syphilitic sore, accompanied by a bubo, fo: which he underwent a salivation, which was actively continued over a period of four months.

Nov. 1843.-He became out-patient, with a large phagedonic sore of the leg.

CASE 6.-Elizabeth F__ contracted syphilis from her husband eight years ago. She placed herself under medical care, was salivated, and considered herself cured in about two months. A twelvemonth ago, she suffered from foul ulceration between the toes. Eight months ago, there appeared upon various parts of the body, especially upon the limbs, large spots of tubercular eruption, which exist at the present time.

Nov. 1st, 1843.-Rupial eruption over the trunk and limbs. CASE 7.-Sarah W- has twice suffered from venereal sores. Upon both occasions, she became profusely salivated by mercurial inunction, which was continued for six weeks at a time.

Nov. 8th, 1843.- She became out-patient, with a large phagedænic sore at the left angle of the mouth, and pains in the limbs.

CASE 8.-William B- underwent a mercurial course for a small superficial sore of the glans penis, contracted four years ago.

Nov. 8th, 1843.-He is suffering from periosteal swellings of both tibir, and severe nocturnal pains.

$\mathrm{C}_{\text {ASE }}$ 9.- - Albert $\mathrm{J}$ - has been twice salivated for primary syphilis. The last attack was five years ago.

Nor. 29 th, 1843.- He became out-patient, with a node of the tibia.

CASE 10.—Henry S- contracted syphilis twelve months ago. A small sore upon the glans penis assumed, at the end of six weeks, a phagedanic aspect, and spread with great rapidity. Cicatrization ensued under active mercurial treatment, by which, however, he was much reduced in strength.

Nov. 28th, 1843.-He became out-patient, with phagedænic ulceration of the fauces, by which the uvula and part of the soft palate have been destroyed. There is the cicatrix of a large phagedænic sore upon the glans penis.

CASE 11.-G. G- states, that three years ago he noticed upon the glans penis a small sore, for which he took mercury in considerable quantity. For six weeks he had given to him three blue pills thrice a day.

Nov. 28 th, 1843.--1he became out-patient, with a large and irregular phagredrenic sore of the left tibia, upon which the periosteum is thickened for a considerable exient. The right testicle is shrunk, and adheres to the scrotum, which is marked by a large and firm cicatrix.

Case 12.-Charles J-contracted syphilis two yenrs ago. He took pills for about two months, during which time the gums became swelled and very tender.

Dec. 1843.- He became out-patient, with phagedænic ulceration of the throat, and tubercular eruptions, with incrustations over the trunk and limbs.

Case 13.-George P- - states, that nine months ago, having contracted syphilis, he underwent a mercurial course, which was continued for six weeks. He took blue pills thrice a day, and rubbed in the strong mercurial ointment at night-time, but the mouth was never much affected. The sore, which was small and superficial, healed under this treatment, without leaving any visible cicatrix. He had been salivated thrice before for other primary venereal affections. About six months ago he suffered from rheumatic pains over the limbs, so severe as to incapacitate him from performing his duties as a soldier, and he consequently obtained his dischar

Dec, 23rd, 1843.-He became out-patient, with tubercular eruption over the whole body, pains in the limbs, and effusion of fluid into the elbow-joint.

CASE 14.-William S-, upholsterer, a married man, of very dissipated habits, has been twice salivated for primary syphilitic sores, which healed without leaving any visible cicatrix.

Jan. 1814.- - Me placed himself under medical treatment, having a bubo in each groin, and the imperfectly formed cicatrix of a large syphilitic sore upon the right elbow and forearm.

CASE 15.-Matilda $S-$, wife of the preceding patient, contracted venereal disease from her husband, about two years ago. Not wishing to communicate to any one the nature of her complaint, she took, by her husband's direction, a great number of mercurial pills, and rubbed-in, freely, the strong mercurial ointment; under which treatment the gums swelled, and she suffered the miseries of a profuse salivation. They lived apart, until the surgeon, who had charge of the husband, pronounced his patient cured; when she, believing that the disease had long been eradicated from her constitution, left her friends, and returned to her husband, at his earnest request. Intercourse with the wife speedily produced in the husband two very painful buboes, of which that in the right groin burst; that in the left was opened, and discharged a quantity of thin yellowish-brown sero-purulent fluid, tinged with blood. The wife next complained of pains in the limbs, and tightness across the chest: then there appeared over the head, trunk, and limbs, a tubercular eruption, which assumed the characters so well known as distinguishing rupia prominens. She then became out-patient, January, 1844. The eruption disappeared, and she regained her strength, under the administration of sarsaparilla, iodide of potassium, quinine, and ather suitable remedies: a profuse discharge, dependent upon ulcerations of the os tincx, was arrested by their cicatrization. In May she went to the sea-side, where she resided with her family, in the enjoyment of perfect health. About the middle of September she returned to town, when she suffered from a most severe attack of rupia prominens, over the head, neck, and extremities; her face became shrunk and pallid; the spirits were depressed, and the appetite failed. Then large spreading phagedonic ulcers appeared over the scalp and face; the alne nasi were soon destroyed; the upper lip was disfigured; portions of the scalp, witl the hair, perished; and the cranial bones became exposed, in a state, partly of ulceration, and partly of necrosis. In January, 1844, she was a well-looking, healthy woman: in January, 1847 , there was scarcely any trace of her former self.

CASE 16.-Samuel S- contracted, in April, 1842, some superficial venereal sores, for which he was treated by an experienced surgeon, who administered mercury, with every proper precaution, and in moderate doses: the gums were but very slightly affected. The sore healed readily, and he remained well for two year's.

May 22nd, 1844.- He became out-patient, with large rupial spots over the whole body; some were in an incrusted state; others were spreading by phagedæenic ulceration.

CASE 17.-William $\mathrm{S}-$, aged twenty-two, sailor, states, that eighteen months ago he contracted venereal disease, for. 
the cure of which he bought a box of pills at a shop. Of these he took, in a month, above one hundred; and found that the gums were become much swelled, and tender. As he was then obliged to set sail for a long voyage, he had then given to him auother allowance of two hundred pills, which he was directed to take by instalments. Under this treatment his health suffered so severely, that he consulted the surgeon of the ship, who directed him to abstain from taking more mercury: he then soon rallied, and remained well for the rest of the voyage. Upon his return to Fingland, where he landed in perfect health, he began to suffer from uight sweats, loss of appetite and of strength. Soon afterwards there appeared, over various parts of the body, large rupial spots, the incrustations upon which covered phagedænic sores, varying in size from a shilling to a half-crown piece.

CASE 18.-John M-, aged eighteen, contracted venereal disease six months ago, and underwent a mild mercurial course.

Feb. 1844.-He became out-patient, with papular eruptions over the whole body, nodes of both tibio, and pains in the limbs.

CAsE 19._John W- has suffered from primary syphilis four times, and upon each occasion has been severely salivated. Jan. 10th, 1844.- He became out-patient. The back of the pharynx was occupied by a phagedæuic ulcer, which had destroyed the uvula, and great part of the sott palate.

$\mathrm{C}_{\Delta \mathrm{SE}}$ 20.-William $\mathrm{T}-$, aged twenty-three, states, that ten months ago he noticed mpon the dorsum of the penis a small ulcer, for which he consulted a neighbouring surgeon Under mercurial treatment the ulcer became phagednenic, and for some time resisted all efforts to promote its cicatrization.

Jan. 10th, 1844.- He became out-patient, with large circular phagedænic sores upon both arms, and nodes of the tibia, accompanied with severe nocturnal pains.

The cases here related illustrate the different modes in which mercury is commonly administered in this country for the cure of syphilis.

Two of the patients (Cases 16 and 18) placed themselves, soon after infection, under the care of experienced surgeons, who treated the disease by a mild mercurial course.

In Cases 1, 3, 4, \&c., the mineral was administered, also under medical superintendence, in larger doses, and its influence was kept up for a period varying from two to four months.

In Cases 14, 15, and 17, it was given in immoderate quantities by unqualified persons, who seem to have entertained the belief, that the greater the absorption of mercury into the system the more permanent and complete the cure. In every instance secondary symptoms ensued; in some, four months; in others, as many or more years after the cicatrization of the primary sore; and it is worthy of remark, that no patients suffered so severely as those who had the misfortune to fall into the hands of persons uneducated for so serious a responsibility, ignorant of the effects which they were producing, and perhaps reckless as to the consequences which might follow.

I do not intend here to enter upon the question as to the relative advantages of the mercurial and non-mercurial treatment of syphilis. That point must be settled by statistics of another kind, and of difficult attainment by surgeons in civil practice. I confine myself to the conclusion which these cases seem to warrant-namely, that whatever power mercury may possess in arresting the progress of syphilitic ulceration, or in removing some secondary affections, it is wholly inefficacious in eradicating the venereal poison; and moreover, that when carelessly administered it injures the general health, and is capable of exerting a most injurious influence, by which the subsequent symptoms resulting from the infec tion may assume an infinitely more formidable and intractable character.

Southampton-street, Bloomsbury-square, April, 1847.

\section{Rebictos.}

Experimental Researches on the Food of Animals, and the Fattening of Cattle. With Remarls on the Food of Man. By R. D. Thomson, M.D., Lecturer on Practical Chemistry, University of Glasgow. London: Longman and Co., Paternoster-row, 1846.

WE may allow Dr. Thomson to state the scope of the present work in the words of his brief and modest preface,-

"The original object of the inquiry was to determine the relative influence of barley and malt iu feeding cattle; but as the opportunity seemed a favourable one for investigating some scientific problems of great importance to physiology, and of extreme value in the physical management of man and animals, advantage was taken of it to extend the experiments so as to include these objects.

" $1 \mathrm{t}$ is well known to those who have been in the habit, of late years, of following the researches which have been undertaken to elucidate the nature of the growth of animals, that it is now generally agreed that the muscular part of them is derived from the fibrinous or nitrogenous ingredients of the food, while the source of animal fat has been disputed. The present experiments seem to demonstrate that the fat of animals cannot be formed from the oil of the food, but must be evolved from the calorifiant or heat-forming portion of the aliment, essentially assisted by its nitrogenous materials. By following out this principle, the author has been enabled to detect an important relation subsisting between the mutritive and calorifiant portion of the food, upon the determination of which, for the various conditions of animals, he considers the laws of animal dieting to depend. He has endeavoured to apply this law to varions articles of human food, and he trusts that the basis has been laid for future rescarches, which may be directed to administer to the health and comfort of mankind, and of domesticated animals." - Preface, pp. v. vi.

The laws here referred to are stated at large in the sixth and ninth chapters of this volume. We shall briefly direct our readers' attention to a few of the deductions. The work itself must be consulted in order to enable the inquirer fully to understand the various important steps which have led to them.

"Food divided according to its functions.-Liebig, it is well known, divides the functions of the food into nutritive and respiratory. I have ventured to employ, instead of the latter term, the expression calorifiant, or heat-producing, so as to give a wider range through the whole system to the function of the unazotised food, than the more local term of respiratory would appear to imply. According to this view, all food is destined for repairing the waste of the body, and for the production of animal heat."- p. 160.

"Law of ultimate composition of food in relation to its power of sustaining animal life.--It may be looked upon as a rule with reference to nutritive bodies, generally speaking, that their power of sustaining the animal system depends, in relation to their ultimate composition, upon the amount of the carbon and nitrogen which they contain. Some lave endeavoured to prove that it is the amount of carbon to which we are to look, in deciding upon the relative nutritive power of the food; while others have advocated the importance of nitrogen in forming such estimates. It seems, however, certain, from a careful study of all the facts, that such general rules cannot safely be adopted, since, in the case of oils, we have examples of substances containing much carbon, which are yet incapable of supplying the waste of the muscular substance of animals, and are therefore to be excluded from the rank of true nutritive principles; while again we have gelatine or jelly containing nearly as much nitrogen as muscular fibre itself; which has been proved to be incapable of supporting animal existence in the manner in which we understand that expression, when applied to beef or true muscular fibre."-p. 111.

"Proportion of these elements to form a nutritive body.-The relation of the two substances is nearly as 70 to 9 of their equivalents, represented by the formula $70 \mathrm{C}, 9 \mathrm{N."}-(\mathrm{p} .113$.

Thus we find that life may be sustained on pure albuminous tissue. Dogs have been supported by it for some months; and the American Indians, near the sources of the Missouri, subsist entirely on dried buffalo flesh; not the fat portions, but the muscular part; and during their subsistence on this dried "pemmican," as they denominate it, they are described by travellers who are intimate with their habits of life, as never tasting even the most minute portions of any vegetable whatever, or partaking of any other variety of food. Gelatine, or glue, seems to be an exception to this law in the nutritive category. We have no examples of animals being capable of subsisting on it; on the contrary, we have proof that animals, when restricted to this species of nutriment, become deteriorated in health. Dr. Thomson thus explains this apparent anomaly.

"When we reflect, that animals subsisting upon vegetable food contain an equal quantity of gelatine, as a constituent of their tissues, with those which have partaken of animal 